\title{
A mechanism based transition research methodology: Bridging analytical approaches
}

\section{Abstract}

This paper is motivated by the discussion in the literature about the strengths and weaknesses of the Multi-Level Perspective framework and aims to provide a response to a number of criticisms.

The paper proposes retroduction as a transition research methodology that is used to identify and test social mechanisms for their explanatory power. The methodology consists in the joint use of case study and system dynamics as modeling and simulation method. The paper discusses how the two methods are used iteratively, and each one complements the strengths and counters the weaknesses of the other. The methodology has particular strengths and implications for the agenda of issues that research on future transitions to sustainability faces currently.

Keywords: sustainability, retroduction, transition, mechanisms, simulation

\section{Introduction}

Sociotechnical transitions research is a relatively new field that places a particular focus on sustainability transitions (Elzen and Wieczorek, 2005; Foxon, 2011; van den Bergh et al., 2011; Markard et al., 2012; Coenen et al., 2012; McMeekin and Southerton, 2012). One of the most widely adopted transition research frameworks is the Multi-Level Perspective (MLP). MLP originates in the work of Rip and Kemp (1998) and has been developed subsequently in Geels (2002;2004;2005;2010), Geels and Schot (2007), Markard and Truffer (2008), Papachristos et al. (2013), and Geels et al. (2016a). The MLP has received a number of critical remarks some of which emphasize issues of agency and the need to develop its methodology (Smith et al., 2005; Shove and Walker, 2007; Genus and Coles, 2008; Vasileiadou and Safarzynska, 2010). Such a methodology should also improve the outline and measurement of niches, regimes and landscapes, the comparability of cases, and enable theory development in a cumulative way (Smith et al., 2010; Holtz et al., 2015).

A number of these critical remarks merit further consideration and motivate this paper: methodological consistency in transition studies, transparency in conveying theory assumptions underlying research, the use of case study data, and the need to maintain the parsimony and tractability of the analysis (Genus and Coles, 2008; Smith et al., 2010). Related to the latter is the need to communicate the researcher's choices and make them more explicit, for example with regard to system boundary definition. The second motivation for the paper is to address the call for reflexive governance (Voss et al., 2006), particularly of future, multi-system transitions to sustainability perspective that requires an iterative process of problem definition, intervention and response.

MLP cases are primarily retrospective (Turnheim et al., 2015), so they must be bridged to other analytical approaches to address the multi-regime processes that may underlie future sustainability 
transitions (Geels et al., 2016b). Reflexive governance requires an endogenous perspective and knowledge of the mechanisms that offer the best leverage to unlock and guide system change towards a desirable direction, anticipate and reorient ongoing transitions, and avoid niche lock-in to unsustainable trajectories (Smith et al., 2010). The need to identify and theorise transition mechanisms was identified early on (Geels, 2002), but very little research followed up on this (Geels and Schot, 2010; Papachristos and Adamides, 2016).

In order to address this gap and part of the MLP critique, this paper starts from a detailed conceptualization of transition mechanisms to achieve four aims. First, to address the call to study transition patterns and mechanisms (Geels, 2002). Second, to keep the MLP relevant for contemporary and future transitions by explicitly incorporating mechanisms in transition research, a requirement for reflexive governance. Third, to address a number of critical remarks the MLP received and increase confidence in the use of the framework. Finally, to develop a mechanism based approach that will bridge case studies and modelling and simulation, and provide the necessary prospective character for the study of future sustainability transitions.

The concept of mechanisms is discussed on several literature streams including analytical sociology and critical realism (Archet, 1995; Hedström and Swedberg, 1998; Archer et al., 1998; Archer, 2000; Hedstrom and Bearman, 2011; Mingers and Standing, 2017). Transitions unfold under major economic changes, and mechanism based theorizing is an appropriate style of organizational research under such conditions (Davis and Marquis, 2005). Identifying causal mechanisms, or "process tracing", in transitions is an appropriate approach when explanatory and independent variables are temporally separated (Mahoney, 2000; Bennett and Checkel, 2014). The paper proposes retroduction as a research methodology to address the call to identify particular patterns and mechanisms in transition processes (Geels, 2002). Retroduction is a metaprocess through which an explanation for a particular phenomenon is developed by identifying and/or postulating mechanisms that can generate it (Sayer, 1992; Collier, 1994; Sayer, 2000; Bhaskar, 2008).

The application of retroduction to sociotechnical transitions faces challenges due to their complexity, and the difficulty to identify mechanisms in operation, and deduce their effects (Hedström and Swedberg, 1998; Hedstrom and Bearman, 2011). In this respect, modelling and simulation has been proposed as a complementary methodological tool to transition case studies (Papachristos, 2014). Thus, this paper aims to bridge the rich qualitative case research used at present with deductive simulation research, where inductive theory building from cases produces new theory and deductive theory development tests it, thus completing the cycle (Eisenhardt and Graebner, 2007).

Recent work on scenarios, narratives and modelling points to the potential to bridge research methodologies but does not discuss mechanisms and therefore it is not detailed (Turnheim et al., 2015; Geels et al., 2016b). Some papers provide a generic overview (Turnheim et al., 2015; Geels et al., 
2016b), others use narratives and established linear optimization models rather than simulation models (McDowall, 2014), or use a combination of different optimization and simulation models (Trutnevyte et al., 2014), or are domain specific and do not address the fundamentally iterative nature of synchronous narrative and model co-development (Moallemi et al., 2017a; 2017b).

The paper argues that the application of the retroductive methodology in sociotechnical transitions research will: (i) help to identify common mechanisms across cases, context and time, (ii) equip the MLP methodologically to address contemporary and future sustainability transitions of multi-energy systems, where small changes in one system may induce major ones in others (Mancarella, 2014), (iii) provide a response to the critique of MLP, and increase confidence in understanding transitions, and (iv) bridge case study and modelling and simulation, and increase the transparency of research design choices, for example with regard to system boundary definition.

The contribution of the paper, along with the retroductive methodology proposed, is the definition and extensive discussion on mechanisms, which in turn enables the provision of guidelines for how to conceptualise, search, and when to stop the search for transition mechanisms in a case. Such guidelines are missing in prior transition research despite the explicit, early call to identify transition patterns and mechanisms (Geels, 2002). The paper outlines the implications, synergies, strengths and weaknesses of bridging case study work and modelling and simulation, induction and deduction (Van de Ven, 2007), and provides a process overview of how the two can work together.

Retroduction with simulation has been applied previously in Papachristos and Adamides (2016) and the argument for using simulation in transition research put forward in Papachristos (2014). The present paper provides a more thoroughly thought out and mature piece on a transition methodology. First, it outlines the criticism that the MLP has received, and that the proposed methodology aims to address. The paper provides an outline of how case studies and modelling and simulation can be combined on pragmatic grounds (Tashakkori and Teddlie, 1998), and co-developed in a transition study, something that previous attempts have not done (e.g. Holtz, 2012; Trutnevyte et al, 2014). System dynamics is considered as a modelling methodology due to its alignment with social science application (Lane, 1999), but the same kind of argument could be developed for agent based modelling. While the paper focuses on the MLP, the proposed methodology may be equally appropriate for application to Functions of Innovations Systems studies (Bergek et al., 2008; Hekkert et al., 2007).

The rest of the paper is structured as follows. Section 2 offers an overview of the MLP, of the criticism it has received, and singles out the particular points that the proposed methodology aims to address. Then section 3 sets the scene for the methodology and provides an overview of mechanisms and retroduction. Section 4 discusses retroduction and why modelling and simulation is needed, and 5 discuss the methodology. Section 6 concludes the paper. 


\section{Sociotechnical Transitions: the MLP Framework}

The MLP is a framework for the study of sociotechnical system change, with a focus on system interconnections and the dynamics of social groups that influence technological change and inertia. The central analytical MLP concept is the sociotechnical regime, which facilitates analysis of what underlies the activities of actors who reproduce system elements. The actors are embedded in interdependent social groups, each with its own regime (set of rules). The MLP distinguishes between technological, culture, science, markets, industry and policy regimes (Geels and Schot, 2007). The sociotechnical regime refers to the inter-regime alignment and coordination of intergroup activities that stabilize sociotechnical trajectories. The MLP has two additional analytical concepts (Geels, 2004): (i) the landscape at the macro level provides gradients for sociotechnical regime trajectories, and (ii) the niche level where radical innovations incubate and proliferate protected from external influences.

Transitions in the MLP framework come about when the sociotechnical regime is destabilised through reinforcing and disrupting interactions that develop between these three levels by (Geels and Schot, 2007): (i) innovations that may develop in niches through learning processes, price/performance improvements and support from powerful groups, (ii) pressures that events may generate or trends at the landscape level that act on the regime (economic, cultural, demographic and other), (iii) internal regime tensions that can accumulate and create windows of opportunity for innovations in niches and, (iv) external influence from other systems, regimes or niches (Papachristos et al., 2013). The transition is finally completed when the social and technical aspects of novel innovations become embedded in the new sociotechnical system.

Transition process research, in its simplest form, focuses on how the nature, timing and intensity of interactions between landscape pressures, the build-up of niches innovations and internal regime tensions may unfold over time, enable or constrain a transition process (Geels and Schot, 2007; Papachristos, 2014). MLP case studies follow a process rather than a variance explanatory style and they don't attribute transitions to single causes or interactions but to to ensembles of multiple interlocking causal influences that reinforce or disrupt each other (Geels, 2011). Different interaction configurations can result in different single-system transition pathways (Geels and Schot, 2007). The range of interaction configurations has been extended to include multi-system interactions (Papachristos et al., 2013).

Contemporary and future transitions to sustainability differ from historical ones (Geels, 2011; Fouquet and Pearson, 2012; Papachristos, 2014; Arranz, 2017). Their study requires an endogenous perspective to identify the drivers that offer the best leverage for system reorientation towards a desirable future direction. The knowledge of leverage points can be used to anticipate and change 
system transitions trajectories, avoid niche lock-in to unsustainable developments, or unlock existing regimes (Smith et al, 2010).

\subsection{Critique to the MLP and Responses}

This section focuses on five points of critique for the MLP to which this article responds to ${ }^{1}$. The first, perhaps most severe critique concerns the epistemological status of the MLP: "the potential contribution of the MLP/transitions framework could be limited to offering a heuristic device that can be used to organise sets of data" (Genus and Coles, 2008, p1442). This critique is consistent with organisational research work about what is a theoretical contribution, where a list of variables or constructs (like niche, regime and landscape) does not constitute theory without an underlying causal logic (Whetten, 1989; Sutton and Staw, 1995; DiMaggio, 1995; Weick, 1995). To produce a sociological explanation, the researcher must theorize openly the events and their contexts, abstract and generalize empirical material, and establish causal connections among narrative sequences so that they can be replicated and criticized. The distinction between a temporal antecedent and a causal one is obscured in narrative and thus additional information and insight is required (Griffin, 1993).

Geels (2011) responded that an open, heuristic framework for transition research may be more suitable than precise formal/deductivist models that are applicable in materialist theories. Heuristic frameworks guide the researcher to think on relevant questions in order to flesh out relevant patterns. In doing so the researcher can utilize "auxiliary theories" to develop middle range theory (Geels, 2007; Geels, 2011) and avoid the development of either grand theories of social life or smaller scope theories (Merton, 1968). For example, a vast literature exists on strategic management (Helfat et al., 2007), organizational change (Poole and Van de Ven, 2004), and analytical sociology (Hedstrom and Swedberg, 1998; Hedstrom and Bearman, 2011). The aim of middle range theory is to provide a satisficing trade-off between the criteria of good theory: accuracy of representation, generality, and parsimony (Weick, 1979). Middle range theory is neither as grand in scope as overarching theories of science and technology, nor as specific as empirical observations. While it is grounded empirically, it sheds some complexity and accuracy in order to increase its generality.

The second criticism concerns the lack of methodological consistency and accuracy in the operationalization of MLP concepts like mechanisms and related methodological requirements. The large uptake of MLP was also driven by the early emphasis placed on technological niches and the availability of many historical cases that were analysed retrospectively as bottom up, transition cases (Berkhout et al., 2004; Smith et al., 2005; Shove and Walker, 2007; Genus and Coles, 2008).

\footnotetext{
${ }^{1}$ For a detailed overview the interested reader can refer to Coenen et al. (2012), Genus and Coles (2008), Markard and Truffer (2008), Shove and Walker (2007), and Smith et al. (2005; 2010), and for a response to Geels and Schot (2007), Geels (2010) and Geels (2011).
} 
The advantage of this bottom up character of these studies is that the system boundary is better outlined. However, historical cases are different than contemporary ones as system interactions and therefore boundaries might change during a transition (Papachristos et al., 2013). Thus, there is a definite need to use methods to map transitions, their boundaries and maintain a tractable, parsimonious analysis (Smith et al., 2010). Geels (2011) responded that MLP concepts can be applied to empirical topics of different scope and the analyst should first demarcate the object of analysis and then operationalise them. Nevertheless, no prescription is offered on boundaries of analysis for MLP studies.

The third criticism concerns how to identify early signs of systems trajectories, anticipate and reorient those that are unsustainable (Shove and Walker, 2007). They point to the need to bridge understanding transitions through retrospective studies with developing the capacity to steer contemporary and future transitions through prospective studies. While Geels (2011) offers no explicit response, this issue is clearly linked to critique on agency, operationalization of regimes and specification of regimes, heuristics, epistemology and explanatory style and methodology. Recent research points to the potential to bridge research methodologies but does not discuss mechanisms and therefore it is not detailed (Turnheim et al., 2015; Geels et al., 2016b).

The critique about system trajectories is important, as a wide variety of future outcomes is possible in path dependent systems, like sociotechnical systems (Mitchell and James, 2001; Pedriana, 2005). If the path dependent evolution of a system is traced and documented in a retrospective case study, this offers an account of how certain phenomena and not others emerged. However, this does not lead to actionable knowledge for future transitions (Goldstone, 1998). Knowledge of causal mechanisms can indicate only why certain phenomena, and not other became possible in the first place, and allow system interventions to produce a useful outcome (Epstein, 2006; Mingers and Standing, 2017). Following the initial call to identify transition patterns and mechanisms (Geels, 2002), considerable work has identified transitions patterns (Geels and Schot, 2007; de Haan and Rotmans, 2011; Naber et al., 2017) but less empirical work has addressed mechanisms with the exception of Geels (2005) and Papachristos and Adamides (2016).

The fourth criticism concerns the evolving/contested nature of the issue of agency (Fagerberg, 2003; Gibson and Early, 2007; Wilson, 2007; Kaisesoja, 2013). Smith et al. (2005), Shove and Walker (2007), and Genus and Coles (2008) raise the issue of relative neglect of agency in the MLP to which the response is: "the MLP is shot through with agency, because the trajectories and multi-level alignments are always enacted by social groups." (Geels, 2011, p29). This statement is inconsistent with Geels and Schot (2007) that adopt structuration theory (Giddens, 1984), and suggest tracing agency to the individual level. Nevertheless, no argument is given for why agency can be traced at the individual or collective level. In fact, he goes on to cite examples like: "rational choice, power 
struggles, cultural discursive activities" (Geels, 2011, p30) that cut across levels. He admits that the point of agency is not well developed and calls for: “...understanding of the mechanisms...” (Geels 2011, p30) through which various levels interact.

Fifth, future sociotechnical transitions require system reorientation towards low carbon intensity trajectories unlike those witnessed in the past (Papachristos, 2014). Low carbon transitions are systemic changes that encompass energy, the economy, and the environment (Rogelj et al., 2015). Their scope requires a search for alternatives to economic growth (van den Bergh, 2011), and a shift in business models towards product service systems (Tukker, 2015). Such changes require more than a sociological, retrospective angle to society and technology coevolution. Nevertheless, little has been done so far to integrate systems thinking approaches, multiple methods and tools in transition research.

\subsection{Conclusions Regarding the MLP Critique}

Part of the critique on the MLP being nothing more than a "heuristic device" (Genus and Coles, 2008), comes from implicit adoption of an organizational research theory definition where heuristics and theory are seen as discrete categories, not a continuum. The response to this critique is that open frameworks may be more suited to investigate transitions than precise models and to transition case studies that aim to illustrate and explore rather than do systematic research (Geels, 2011). Openness, flexibility and even vagueness (Bacharach, 1989) are unavoidable in the initial stages of any new research endeavour such as transition research, and they facilitate creativity and links to other theories and ontologies (Geels, 2010).

Sociological explanation requires that events and their contexts be theorized openly, factual material abstracted and generalized, and that causal connections in narrative sequences are established in a way that can be replicated and criticized. The development of such sociological explanations requires information and insight in addition to a narrative (Griffin, 1993). Nevertheless, properties such as closure, precision and accuracy in operationalising concepts, having pragmatic usefulness and achieving theoretical cumulation through systematic research are also necessary (Scharpf, 1997). Progress from a stage of openness to a stage of closure implies that theory is seen as a continuum (Weick, 1995) rather than a distinct category ${ }^{2}$.

There are two potential responses to the critique of Genus and Coles (2008). The first is that it comes from a particular perspective on organization science theory and it doesn't stand if a different perspective is adopted (Hall, 1999; Kagan, 2009; Goertz and Mahoney, 2012). The second is to adopt the organization science perspective on theory and develop MLP into a more closed theoretical

\footnotetext{
2 There are several views on theory (Blaikie, 2007; Hall, 1999). The author thanks Frank Geels for this point.
} 
proposal. A substantive response to the Genus and Coles criticism, if this perspective on what constitutes a theoretical contribution is adopted, requires that the MLP theorizing process and its foundations are reconsidered and improved (Weick, 1989). Subsequent sections try to address the foundations and requirements of mechanism related theorizing in transition research.

The introduction of mechanisms has implications for the five MLP criticisms. First, mechanisms can facilitate a shift of MLP case research from a heuristic device used to organise sets of data epistemology to a process that can explain transitions, and thus address the first critique. Second, mechanisms can be traced to the collective and individual levels thus they address the neglect of agency as well. Third, if mechanism based research is pursued consistently with the proposed methodology, it can improve methodological consistency. Fourth, mechanism research integrated with system dynamics can provide some insight on what could bring about system change and thus address the fourth criticism. Fifth, mechanism based research facilitates the integration of a systems approach to transition research as it is consistent with system dynamics research (Mingers, 2014; Mingers and Standing, 2017).

The discussion in section 2.1 outlines the points the proposed transition methodology must address to identify mechanisms in a consistent and transparent way, and explain a transition through retroduction rather than by matching narratives to transition pathways which tends to be encouraged by the stylised transition pathways in the literature that serve as a template (Geels and Schot, 2007; Geels et al., 2016a). The application of the methodology to contemporary and future transitions will enable a more systematic exploration of future transition pathways, the impact of system interventions, and may lead to extensions to the original set of pathways. The discussion in sections 3 and 4 provides the theoretical background for the methodology proposed in section 5. Most importantly its attributes constitute an improvement for the five points of MLP critique discussed in section 2.1.

\section{Foundations of the Proposed Methodology}

Several definitions of theory have been proposed (Harre, 1970; Bacharach, 1989; Gioia and Pitre, 1990; Mintzberg, 2005). Theory development is the outcome of a long winded process in which theories at work approximate fully fledged theories (Corley and Gioia, 2011). During this process, all the researcher has to work with usually are appropriate references, data, definitions, variables, narratives, diagrams and hypotheses, which do not constitute theory on their own, but are part of the building blocks for it (Griffin, 1993; Sutton and Staw, 1995). The implication is that theory can be viewed as a dimension (Weick, 1995). Researchers progress along this continuum through an "interim struggle" until they arrive (if ever) at a fully fledged theory at the end (Mohr, 1982; Mintzberg, 2005).

Theory development has been likened to a process of evolutionary "disciplined imagination" (Weick, 1989), where researchers propose, test and select among theory variants. The quality of 
theory developed is higher when the subject of inquiry and the various propositions, are stated more accurately, a larger number of variations and experiments are generated, and more diverse criteria are applied consistently to them. A significant bottleneck in this is that researchers are both the source of variations and the ones that apply selection criteria. In effect, they run a mini evolutionary system in: "a head that suffers from bounded rationality" (Weick, 1989, p529).

As the system description is progressively enriched, it becomes difficult to maintain a clear picture of how mechanisms may be linked to behaviour in a narrative (Griffin, 1993), and trace their interactions through to their impact because of complexity, thus selection becomes more difficult. Narrative descriptions and mental experiments are essential but are unsatisfying as an explicit and replicable causal framework (Griffin, 1993). Narratives also face limiting returns that make the identification and collection of relevant case data progressively more difficult. The only way to complete the selection step is to test these variations through real world, or computer simulation experiments (Weick, 1989). The nature of sociotechnical transitions makes the use of real world experiments difficult, although work exists on transition management experiments particularly in urban areas and water systems (De Haan et al., 2015; Gorissen et al., 2017). So far, narratives have been used primarily although simulation has gained ground (Papachristos, 2011; Holtz et al., 2015; Papachristos, 2017; Köhler et al., 2018).

Multi system transition research is a step increase in terms of complexity compared to single system case research, which is the norm and provided the foundation for the development of the MLP to a single system transition framework. Nevertheless, multi-system interactions are a promising research area because they are directly linked to sustainability transitions (Geels, 2011) and there is scant work on them (Raven and Verbong, 2007; Papachristos et al., 2013). Moreover, former antagonistic systems regimes do not necessarily disappear completely. For example, in urban related transitions cars and bicycles coexist (Shove, 2012; Hodson et al., 2017). In this respect, there is still considerable scope for further work that will apply the methodology proposed here to new cases.

The proposed methodology must cope with the increase in complexity in multi-regime interactions and transitions, and facilitate theory development. The use of an established narrative approach leads to theoretical accuracy (Weick, 1989). Modelling and simulation can cope with complexity and leads to parsimonious theoretical conceptualizations and simplicity (Davis et al., 2007; Harrison et al., 2007). The pragmatic combination of the two methods offers a better trade-off between accuracy, simplicity and generality as they sit on opposite sides of the research strategy spectrum (Figure 1), and has some implications when research is viewed as a decision-making process (Morgan, 1983). 
Selection among alternative explanations with an open ended case research approach may delay potentially the decision on when a satisfactory explanation has been reached, because confidence in a case study is built through analysis and corroboration of data. The use of modelling and simulation can work in synergy with case study research in the proposed methodology as a decision support tool for the entire data collection and research process rather than its final step (Oreskes et al., 1994). The iterative search for an explanation and relevant data can proceed in parallel with modelling and simulation and case study research as both require rich, detailed qualitative description (Homer, 1996; Sterman, 2000; Yin, 2003). A milestone is reached when the model can reproduce the phenomenon of interest and thus be considered as an explanation.

In summary, the methodology is based on a particular conception of theory and aims to provide a means to research contemporary, multi-system transitions to low carbon trajectories. The motivation is to address the call to identify transition mechanisms through a combination of case study and simulation methods. The following sections 3.1-3 provides the foundation and section 4 shows how this is done.

\subsection{Social Mechanisms}

An early definition of social mechanisms is: "social processes having designated consequences for designated parts of the social structure" (Merton, 1968, p43). Under this definition social mechanisms are the elementary building blocks of middle range theories (Hedström and Swedberg, 1998; Hedström and Ylikoski, 2010). Thus, social mechanisms are an appropriate building block for the MLP which also aims at developing middle range theory (Geels, 2007).

Several mechanism definitions exist in the literature (Glennan, 1996; Machamer et al., 2000; Hedström, 2008; Hedström and Bearman, 2009; Hedström and Ylikoski, 2010). The definition adopted here is that (Torres, 2009, p247): mechanisms are complex systems composed of entities organized in time such that (i) through engaging in activities they produce a phenomenon, and (ii) the activities in which the mechanism's entities engage are characterizable as invariant generalizations. An invariant generalization implies stability under some related changes and interventions (Tsoukas, 1989; Woodward, 2002), and requires that mechanism components must be independent in order to allow one to trace how changes in them impact the overall system behaviour. Invariance implies that mechanisms should allow for counterfactual inferences that are associated with control (Machamer et al., 2000; Woodward, 2002).

A mechanism has further characteristics (Hedström and Ylikoski, 2010): (i) it is linked to a particular effect it produces, (ii) it is an irreducibly causal notion, (iii) it forms a hierarchy with other mechanisms, (iv) it has a structure which can be linear or non linear (Bunge, 2004), (v) it may refer to an easy or difficult to observe causal factor (Gerring, 2010), and (vi) it may refer to an explanation that presumes probabilistic or highly contingent relations (Gerring, 2010). A final characteristic of 
mechanisms is their temporal nature. Mechanisms may consist of a sequence of actions that involve different social elements e.g. a diffusion process, but they can also involve recurrent action of the same elements e.g. an escalation process (Mayntz, 2004).

\subsection{The Search for Mechanisms}

There is no established method for mechanism search because processes do not come as discernible given units (Bunge, 2004). The search for mechanisms involves imagination (Weick, 1989), use of available data and making conjectures (Bunge, 2004). The researcher picks a sequence of the ongoing process and justifies why it is considered as the explanandum (Mayntz, 2004). Then through process tracing the researcher can identify mechanisms and initial conditions that link explanatory with independent variables and generate jointly the observed outcome. Moreover, the researcher can generalize about what processes can occur in the world (Mayntz, 2004; Collier, 2011; Bennett and Checkel, 2014).

The focus on mechanisms breaks up the original, explanation seeking, "why" question into a series of smaller questions about the causal process: What are the participating entities and their relevant properties? How the interactions of these entities are organized temporally? What factors could prevent or modify their outcome? (Hedström and Ylikoski, 2010). The search for mechanisms presupposes epistemologically that generalizable properties can be abstracted from historical processes. If a mechanism is defined ontologically as a class of processes that display the same kind of causal structure, and mechanism statements are defined as causal generalizations about such processes, then a mechanism cannot be observed directly (Tsoukas, 1989). The operation of a mechanism can be observed in a specific instance provided that some observable, real event sequences have similar properties, in the same way that analytical constructs are observed via the indicators that operationalize them (Mayntz, 2004).

Further insight into searching for mechanisms is provided by taxonomies of mechanism types (Coleman, 1986; Tilly, 2001; McAdam et al., 2001; Opp, 2005). The first type covers the macro-tomicro link (Figure 2). Hedström and Swedberg (1998) call it a situational mechanism, a systematic link from a social structure, event or state, to the beliefs, desires, and opportunities of individual actor(s). Examples are the belief-formation and preference-formation mechanisms such as those expressed in the idea of reference groups (Merton and Rossi 1968; Boudon, 1988). The second type, at the micro level, is called action-formation mechanism and links specific combinations of individual desires, beliefs, and action opportunities to a specific action. The mechanism based approach to social science does not subscribe to an axiomatic position according to which a specific action theory should be used for all purposes (Hedström and Ylikoski, 2010). The requirement that mechanism based explanations have to cite the actual causes of the phenomenon to be explained often makes rational 
choice explanations unacceptable, as they are built upon implausible psychological and sociological assumptions.

Finally, transformation mechanisms cover the micro-to-macro link of how interactions of groups or individuals produce some collective outcome. Examples include Schelling's (1978) segregation model and game-theoretic models such as the tragedy of the commons, and neoclassical market models (Scharf, 1997). From this taxonomy it follows that a mechanism based explanation is not identical with a bottom up explanation (Opp, 2005). For example, Steinhilber et al. (2013) consider six mechanisms in the transition to electric vehicles that can be classified as situational: regulation, governance and $\mathrm{R} \& \mathrm{D}$ incentives that condition the context individual actors face, action formation: infrastructure investments and technology development that link particular motivations to actions, and transformation: business models and consumer incentives that produce some outcome through the collective production and appropriation of value.

\section{INSERT FIGURE 2 HERE}

Processes identified in the causal reconstruction of a particular transition case can then be formulated as mechanism statements. They must: (i) make mechanisms explicit and detailed, and (ii) support its assumptions by relevant empirical evidence (Hedström and Ylikoski, 2010). The statements should provide (Mayntz, 2004): (i) the level of reality mechanisms refer to, (ii) their degree of conceptual abstraction, (iii) the scope of their claimed applicability at a given level of abstraction, and (iv) their sequence and timing (Sutton and Staw, 1995).

\subsection{Concluding the Search for Mechanisms}

The question of when does the search for mechanisms end can be answered from an epistemological and ontological perspective. From an epistemological perspective, mechanisms traced to lower levels implies a hierarchy (Hedström and Ylikoski, 2010), and the assumption that within every covariation relation (Macro $1 \rightarrow$ Macro 2) there is a mechanism (Micro 1) and within that covariation relation even lower level mechanisms (Micro 1a,b) which can be known (Figure 3). A first condition is that this process should end when the researcher is confident about the underlying assumptions of mechanisms (Hedström and Ylikoski, 2010). A second condition is when the boundaries of the existing literature have been exceeded and new knowledge has been created (Anderson et al., 2006). A third condition suggests the investigation of contiguous levels of analysis, one level above and one level below their focal phenomena (bracketing rule) (Hackman, 2003). For example, if a researcher is interested in understanding individual behaviour, the key mechanisms may reside in group structures and processes (one level above) and in individual cognition and emotions (one level below). 


\section{INSERT FIGURE 3 HERE}

From an ontological perspective, methodological individualism assumes that all causal powers ascribed to social groups are reducible to the aggregates of causal powers of their individual members. Nevertheless, organized social groups and larger social structures are among the core explanatory factors of large scale long term social changes in historical and comparative macro-sociology (Kaidesoja, 2013), political processes (Scharpf, 1997), corporate competition (Stinchcombe, 1998) and organizational ecology (Hannan and Freeman, 1989). Macro social mechanisms are justified ontologically as social reality is stratified, and each level exhibits emergent properties and is sustained by relationships valid only at that particular level.

Two main arguments are put forward for this. First, the idea that mechanisms form hierarchies suggests that social entities above the level of individuals can form parts of social mechanisms, if they are shown to be relatively durable collective agents with characteristic emergent capacities and activities (Kaidesoja, 2013). Second, from a collective cognition perspective, many cognitive processes transcend the boundaries of the individual brain and are distributed across our environmental structures, information processing technologies and interactions with people (Weick and Roberts, 1993; Wilson et al., 2007). Thus, agency can be attributed to collective social entities as long as they endure (Weick and Roberts, 1993).

In conclusion, multi-level and multi-actor processes can be explained by mechanisms. Their use in MLP research provides a response to its criticism about agency not being considered seriously (Smith et al., 2005), and resolves the inconsistency in Geels own statements about it (Geels and Schot, 2007; Geels, 2011).

\section{A Retroductive Methodology for Sociotechnical Research}

According to the critical realist perspective retroduction is a metaprocess through which given a description of an empirical phenomenon: “...events are explained by postulating (and identifying) mechanisms which are capable of producing them..." (Sayer, 1992, p.107), and the conditions for the occurrence of the phenomenon are reconstructed (Bhaskar, 2008). Retroduction is suggestive of what may be part of the real world and through this a novel understanding about the world is introduced (Wuisman, 2005).

Retroduction starts with a description of the significant features of the Unexplained Phenomenon $X$ for which a Theoretical Gap exists in the knowledge (Figure 4). Then $X$ is recontextualised as a more general phenomenon by abduction, and a range of Dynamic Hypotheses $H$ are put forward, each consisting of an ensemble of generative mechanisms. Subsequently, their validity is assessed by Deduction of their logical consequences. Finally, if the patterns of the deduced 
consequences do not match those derived through case analysis, then a new cycle of abduction, deduction and induction takes place.

\section{INSERT FIGURE 4 HERE}

\subsection{The need to test transition mechanisms}

The need to test mechanisms arises out of the methodological requirement to evaluate their explanatory power for some Unexplained Phenomenon $X$ (Figure 4). The evaluation requires the demonstration of mechanism consequences, observable or not (Sayer, 1992). There are three reasons to do so. First, the use of inductive methodology can lead to a correlative logic, where "if Condition then Pattern" statements are made based on the regularity with which transition patterns are observed. For example, if pressures accumulate in the regime then incumbent member activities become misaligned and may lead to a transition pathway (Geels and Schot, 2007).

Caution is warranted in inferring causality via an MLP narrative, as certain events placed on a timeline may suggest causation but their correlation with transition patterns does not imply necessarily a causal relation (Sayer, 1992). Furthermore, such conditional MLP logic was derived from observed regularities in historical transitions (Smith et al., 2010). The use of the same MLP logic for contemporary and future transitions may be problematic because the social and technological context has changed and transition drivers differ as well with historical cases (Fouquet and Pearson, 2012; Arranz, 2017). The system transitions of the past will not repeat necessarily. In fact, it is desired that they do not since, they lead to the current sustainability challenges (Papachristos, 2014).

Second, observing a transition pattern and inductively stipulating conditions for it, can lead to fallacious inferences even in a stable social context. For example, mechanisms that reinforce and oppose a transition may operate with equal intensity and result in stagnation (Tsoukas, 1989). A researcher may infer that these conditions will always result in a stagnant situation, but any change in their nature, intensity or timing may alter the result. The converse is also possible. Opposing mechanisms may operate but a transition may initiate nevertheless, in an undesirable trajectory. Thus, while it is necessary to identify empirical correlations, an analytical shift requires tests of mechanism nature, timing and intensity in the deductive step of retroduction to provide a measure of their validity.

Third, transition research is concerned principally with structural causes, where multiple factors lie between cause and effect (Mahoney, 2000), due to system feedback, delays and processes of accumulation (Geels, 2005; Raven, 2007; Naber et al., 2017). For each covariational relation there is a plethora of plausible causal mechanisms available in the literature (Gerring, 2010). The abductive step from effects to transition mechanisms must consider the fact that innovation at a fundamental level is not linear (Abernathy and Townsend, 1973), and that innovation mechanisms may not be 
linearly additive (Manicas, 2006). The resulting mechanisms must be tested and there are some difficulties related to this.

\subsection{Overcoming Difficulties in testing MLP explanations}

Learning about complex social systems while being embedded in them is difficult because of a number of cognitive limitations that apply to organization theorists too (Astley and Van de Ven, 1983; Sterman, 1994; Kahneman, 2011). Humans adopt a simplistic cause and effect view of events, they do not appreciate correctly system delays, feedback processes (Sterman, 1989a,b; 2008; 2010) and the possibility that the intensity of feedback loops in the system may change (Diehl and Sterman, 1995). Research provides empirical evidence that people understand poorly accumulation or depletion processes (Sterman and Sweeney, 2007; Cronin et al., 2009; Aramburo et al., 2012). They often correlate a system's output(s) to its input(s) despite the fact that accumulation is a ubiquitous process, found in most temporal and organizational scales (Cronin and Gonzalez, 2007; Cronin et al., 2009). Even scientists can fall into traps if their results look reasonable (Nuzzo, 2015). The implications of this are ubiquitous, they are relevant for climate change research (Sterman, 2008), and link inevitably with sustainability transitions research.

Hence, the deductive step in Figure 4 cannot be performed mentally with confidence because transition phenomena involve multiple feedbacks and accumulation processes (Geels, 2005; Geels and Schot, 2007; Raven, 2007; Naber et al., 2017). Inferences and policy related insights may be of limited value or work against the intended aims of a transition study. Furthermore, empirical learning through feedback and experimentation is also not practical as transitions unfold over decades and real world experiments are time consuming and costly. Thus, it is not possible to calibrate human intuition about how such systems might work in the future by virtue of human experience alone.

The fact that the development of MLP transition typology has been based primarily on single system case studies is an indication of human cognitive limitations when it comes to multi-system analysis. A multi-regime transition typology has not been developed despite the role of outsiders in historical and contemporary transitions (Papachristos et al., 2013; Arranz, 2017). Theory development in this direction is necessary because future transitions to sustainability are expected to be multi-regime and multi-system in nature (Lauridsen and Jorgensen, 2010; Smith et al., 2010; Geels, 2011). Therefore, sole reliance on transition case studies, as it has been the practice so far, is inadequate for the future.

Modelling and simulation is a way to overcome the cognitive limitations discussed and address transitions to sustainability. The combination of case study and modelling and simulation in retroduction, retains the context and detail of MLP transition narratives while increasing confidence in understanding transition dynamics and drawing conclusions. The effectiveness of the pragmatic, 
mixed method use of narrative and simulation is based on the assumption that they do not share the same weaknesses or potential for bias, and that the strengths of each method counter the weaknesses of the other (Jick, 1979; Johnson et al. 2017). Nevertheless, there are some limitations to the use of modelling and simulation (Davis et al., 2007; Harrison et al., 2007). For example, it is impossible to validate completely a model in the sense of its claims to truth (Oreskes et al., 1994; Sterman, 2000).

\section{Outline of Methodology}

The proposed retroductive methodology integrates case study and modelling and simulation and this section discusses how they are combined together in three steps. In the first step, mechanisms are identified, temporal assumptions are made explicit, and their representations are made more accurate and integrated in a model. In the second step, these mechanisms are varied to generate alternative explanations that are tested systematically through a diverse range of tests. Finally, one is selected by applying consistently more diverse criteria to them at the selection step. The two methods work in synergy as a case study provides a rich description of a transition or input for models, and the necessary context for model results (Winsberg, 2006), and evaluate their implications because the resultant type of knowledge is itself complex and is a statement of research choices and constraints (Pidd, 2004). Hence, while the methodology steps are outlined in a linear fashion in the following sections, the researcher will engage iteratively in retroduction.

\subsection{Step 1: Dynamic Hypothesis Development}

A necessary first step to go from data to a theoretical understanding, is to postulate explanatory mechanisms for the process (Van de Ven, 1992; Langley, 1999). The MLP employs 'process theory' as explanatory style (Geels and Schot, 2010), and process theories explain outcomes in terms of event sequences and the timing and conjunctures of event-chains (Pettigrew, 1997; Abbott, 2001; Langley, 2007; Langley et al., 2013). The development of a Transition Narrative is necessary to capture accurately the complex interactions between agency and changing contexts, time, event sequences, and actions (Griffin, 1993; Pentland, 1999; Abell, 2004).

Such narratives are developed commonly in transition case studies (e.g. Turnheim and Geels, 2012; 2013). The context and accuracy of narratives is consolidated in order to match the transition case to one, or more of the proposed transition pathways (Geels and Schot, 2007). A causal narrative that conveys a System Understanding of Transition can then be produced using the MLP as a heuristic device (Pedriana, 2005; Geels, 2011). The aim in this first step is to identify and categorize the key processes and interactions that drive system behaviour in niche(s), regime(s) and landscape, and identify mechanisms in line with the discussion in section 3.2-3.3. 
The question of why an event sequence happened is broken down into a series of questions about actors and entities, their properties, and their interactions in time. For example, an aggregated diffusion process of a disruptive technology is the outcome of a series of adoption events and interactions between agents. To return to the example in section 3.2, the transition in car transport will involve likely the diffusion of electric vehicles. This car transition involves situational, action formation and transformation mechanisms that can be broken down into the study of interactions of early adopters, early majority, mainstream users and laggards (Rogers, 2003) and further disaggregated to the individual level. However, the search for mechanisms often stops at the level of certain user groups of market segments that can be characterised reasonably in terms of their preferences and thus their propensity to exert agency under a range of options. Data can then be collected accordingly to develop hypotheses and address research questions with the case. In the electric vehicles case, data were collected through semi-structured interviews with key stakeholders within the automotive sector, and were supplemented through scientific literature, and published government documents (Steihilber et al., 2013).

Causal loop diagrams (CLD) can then be developed to produce a Dynamic Hypothesis of how interlocking, reinforcing or disrupting feedback loops operate for each user group and other relevant agents e.g. competing technology firms. The use of CLDs to represent multiple interlocking mechanisms is a standard part of system dynamics methodology (Sterman, 2000; Lane, 2008). The development of a CLD requires additional factual and counterfactual questions about the observed events in order to focus on those that are deemed to be causally significant, a process termed “disciplined imagination" (Weick, 1989; Griffin, 1993). CLDs can also provide the means to address the need to map transitions in a more stylized way (Smith et al., 2010). For example, transition processes of de-alignment, re-alignment (Geels and Schot, 2007) can be cast in terms of shifting dominance of disrupting and reinforcing mechanisms that unravel a regime and constitute something new in its position.

The Dynamic Hypothesis is a provisional explanation about what generates system behaviour in theory (Sterman, 2000). The observed system behaviour can be represented through temporal patterns by Abstracting and Simplifying from the narrative, and provide a description that contains less than the total detail of their underlying transition process while they still reflect some of its fundamental aspects (Richardson, 2005; Janssen et al., 2009). It is crucial that such temporal patterns reflect all kinds of available data, quantitative or qualitative. Qualitative data are used in transition case studies and can serve as a main source of information in system dynamics methodology (Wolstenholme, 1990; Sterman, 2000; Luna-Reyes and Andersen, 2003). For example, one source of important data is the experience and knowledge of those that are familiar with its history of performance and artifacts (Forrester, 1961; Randers, 1973), that can be elicited through interviews 
(Ford and Sterman, 1998). Subsequently, a Dynamic Simulation is constructed. The benefit of modelling and simulation is the rigour it introduces, as it compels researchers to face issues and assumptions they may have acknowledged but addressed or stated vaguely (Harrison et al., 2007; Davis et al., 2007). Nevertheless, model simulation has limitations too (Geels et al., 2016b). The use of a model along a case study can enhance the reliability and validity of research, and help the researcher explore system behaviour further. The aim to develop better explanations through the combined use of methods requires step 2 and 3.

\subsection{Step 2: Alternative Hypothesis Development}

The development and juxtaposition of alternative Dynamic Hypotheses to select one through a diverse range of criteria is preferable to persistence onto a single one, that is stretched to fit the data (Mitroff and Emshoff, 1979). The researcher varies the assumptions and mechanisms that underlie a Dynamic Hypothesis through disciplined imagination (Weick, 1989), to generate a range of corresponding, alternatives and simulation models ${ }^{3}$. Such boundary adequacy tests are an integral part of system dynamics methodology (Sterman, 2000; Burton and Obel, 2011). They require rigorous search and consideration of available and additional data to determine the concepts, and variables that are significant and treated endogenously, those treated exogenously and those omitted (Richardson and Pugh, 1981; Sterman, 2000).

The search for alternative hypotheses can serve different purposes. If the study is retrospective, the aim is to explain a transition and the search stops when a satisfactory explanation is reached. If the study is prospective the aim is to achieve some targets in time through robust policies and enhance system trajectory adaptation to exogenous effects (Haasnoot et al., 2013). The search stops if a threshold of performance is achieved, or it is demonstrated that it is not possible to achieve it. In either case the model sensitivity to variables has to be explored. If the model is not sensitive to a variable then it could be set constant or be omitted altogether to create a more parsimonious transition explanation. If the model is sensitive then the search for what influences the variable, or ways to influence the variable can generate more elaborate hypotheses.

For example, the model boundary may need to be expanded to include new variables and feedbacks that can overcome policy resistance. Expanding the boundary of a model can have effects much greater than those introduced by disaggregating existing model structure (Rahmandad and Sterman, 2008). Boundary exploration is particularly relevant for future oriented studies as the greater the time horizon the greater the system boundary under consideration. Furthermore, a range of

\footnotetext{
${ }^{3}$ The generation of many explanations does not imply the development of many models from scratch. Differences in models can range from one equation to whole modules, or the architecture of the model. The inclusion, or removal, of those from a model suffices to treat it as a new model.
} 
different representations of the system that can draw on different ontologies or scientific paradigms may be produced (Gioia and Pitre, 1990).

Boundary tests are difficult because they encompass articulation of all, theoretically plausible mechanisms for a given covariational relation. Unlike statistical correlation tests, this is an open ended task as mechanisms may contain underlying ones, or other mechanisms may offer better alternatives (Gerring, 2010). The syntax of a modelling language facilitates the systematic generation and test of candidate explanatory mechanisms (Harrison et al., 2007) to substantiate their theoretical validity and increase the confidence in selecting one (Goldspink, 2002).

\subsection{Step 3: Selection \& Retention}

In this step one candidate Dynamic Hypothesis is selected based on the criteria of parsimony, testability, logical coherence and explanatory power i.e. how well it reproduces the real phenomenon (Pfeffer, 1982). Gerring (2005) provides a more nuanced list of criteria. Explanatory power increases when evidence in support of its assumptions are presented and if it is demonstrated why alternative hypotheses and their assumptions are unlikely to hold (Siggelkow, 2007; Hedström and Ylikoski, 2010).

A process of Pattern and Timing Testing underlies these three steps where a comparison of observed patterns with those derived theoretically from the dynamic hypothesis for the process (Trochim, 1989; Bitektine, 2008). The theoretical pattern is derived by deduction from the postulated mechanisms for the transition process. If it matches the empirical pattern then this increases confidence that the proposed theory is an explanation of the observed transition. Pattern matching techniques have been explored in system dynamics where the behaviour of the model is compared to real world patterns (Barlas, 1989; Sterman, 2000), and elsewhere, for example in ecological modelling (Railsback and Johnson, 2011).

As an initial guideline towards this, any attempt at pattern matching must consider their sequence and evolution in time, and the level they are found (Mohr, 1982; Lerner and Kaufman, 1985; Abbott, 1990), as in transition research different events can be found at different ontological levels. Pattern matching requires the compilation of a temporal sequence of observed events to attempt to determine causality. Then a comparison with theoretically deduced events can be made to match their pattern and timing by observing the following conditions (Yin, 2003): (i) some events precede others while the reverse is impossible, (ii) some events occur contingent on others, (iii) some events can follow other events only with a certain delay, and (iv) certain types of events occur only during specific time periods. Pattern matching does not remain opaque to the reader if model documentation and reporting guidelines are followed (Sterman, 2000; Rahmandad and Sterman, 2012; MartinezMoyano and Richardson, 2013). 
Nevertheless, a gap exists in transition literature and a challenge for the proposed methodology. Descriptive MLP studies abstract usually their empirical findings into stylised patterns, but the development of cross-case quantitative indicators for transitions remains a major theoretical gap. Indicators are necessary to compare these empirical patterns to a simulation derived theoretical pattern. A second challenge in bridging cases and models is the development of a broadly shared conceptualisation and framework that can act as a channel for dialogue between case and model based work. The consistent application of the proposed methodology to transition cases is a step in this direction. Nevertheless, this challenge requires the development of transition indicators for example for the concepts of regime inertia, path dependence, and niche momentum. Ideally two or more researchers would be involved in such a process versed in case, theory development, and modeling where the modellers take up information and empirical patterns, develop models and come back to other researchers with simulated patterns that can be compared to theoretical and empirical patterns.

The application of the methodology steps proceeds from left to right in Figure 5, towards greater simplicity. The process starts from a Transition Narrative development which provides the necessary context and details of the transition ". A System Understanding of Transition is developed which is relatively simplified but conveys the essent of transition dynamics. Then a Dynamic Hypothesis is produced by Abstracting \& Simplifying the key elements and patterns of the Transition Narrative. Disciplined Imagination yields the underlying mechanisms drawing on the researcher's System Understanding of Transition which is turned into a simulation model to deduce its consequences, and corroborated with the Dynamic Hypothesis through Pattern and Timing Testing using data documented in the case analysis (Figure 5).

\section{INSERT FIGURE 5 HERE}

The proposed methodology does not offer a decision heuristic for "what" will be the subject of research: a complete historical transition, or part of an ongoing transition. The "how" involves a combination of case study and modelling work. The application of the methodology might reveal the need to better account for behavioural aspects of transitions, or political processes, in the narrative and in the model. The "how" might result in "what" the study aimed to describe being different than that it describes at the end.

In summary, section 5 discussed the proposed methodology and how in each step transition narratives, and modelling and simulation complement each other in a pragmatic way. The methodology provides a response to the 5 critique points discussed in section 2.1 (Table 1). First, it provides a way to begin to identify mechanisms. If this helps to build greater confidence in the nature of causality, then the MLP may be able to move beyond its current status as a heuristic. Second, mechanisms can be identified and traced to the collective and/or individual level, depending on the 
needs of the case at hand. Thus, they are an improvement on the neglect of agency that MLP has been criticized for. Third, the introduction of an established modelling methodology (Sterman, 2000) would also address the lack of methodological consistency, and increase rigour, transparency, and tractability as system dynamics has established rules for communicating models and results (Rahmandad and Sterman, 2012; Martinez-Moyano and Richardson, 2013). Part of this includes the use of causal loop diagrams as a representation tool for of transition dynamics. Fourth, the identification of mechanisms provides actionable knowledge for how to change the behavior of system elements and thus its trajectory. Fifth, the integration of system dynamics, equips the MLP for the study of complex, multi-system transitions to sustainability and thus, keeps it relevant for the future. Moreover, there is an element of convergence between the foundation of system dynamics as a method and MLP as a framework as both deal with long term issues and large-scale system change.

\section{INSERT TABLE 1 HERE}

\section{Conclusions}

The contribution of this paper is its proposed a retroductive methodology for transitions research that combines case study and modelling and simulation on pragmatic grounds (Tashakkori and Teddlie, 1998). Two issues motivated this research: (i) the critique the MLP received (Table 1), and develop a methodology for identifying transition mechanisms and patterns, and (ii) the call to equip MLP for multi-regime and multi-system future sustainability transitions. The proposed methodology has retroduction at its core, and requires that generative mechanisms for a transition are postulated. Modelling and simulation is used to test them. Simulation is necessary to study the nature, intensity and timing of interactions during a transition and identify the signs of change. The use of mechanisms in an MLP context goes beyond the provision of a way to categorise events hence, the methodology overcomes the criticism of Genus and Coles (2008) about the theoretical contribution of the MLP.

The integration of case studies and co-development with modelling and simulation increases considerably methodological consistency while it maintains the tractability of transition analysis even if complete model validation is not possible. Causal loop diagrams and the simulation model provide a record of the assumptions that underlie transition explanations. Thus, the combination of case and modelling enables greater comparability across transition cases. If mechanism based explanations are identified that are generic across several case studies then this will result in further integration of theory between different transition pathways, various mechanisms for niche regime interactions, and geography. Their systematic exploration by varying interactions and their attributes on a case by case basis, should provide sufficient detail and understanding of the system mechanisms in operation, and provide the basis to alter the system trajectory, then learn to manage, and then steer it to a sustainable trajectory. 
Retroduction along with modelling and simulation provides a means for a shift from historical research of single system/technology transitions to multi-system/technology sustainability transitions, which are central to the future research agenda of the MLP. Retroduction enables a better appreciation of the factors and the ways in which multi-system behaviour and transitions are driven with increased confidence. The methodology can be the basis for the development of principles to bound and measure niches, regimes and landscapes because it forces the classification of variables that can help operationalize the theoretical concepts on a case by case basis e.g. indicators of niche stability. Future application will aim to build on prior work as well as explore political and behavioural aspects of sociotechnical transitions, a research theme that is extremely relevant.

The challenge of modeling and simulation integration in transition research lies in characteristics that are pertinent to transitions (Köhler et al., 2018): changes in culture, societal values and political struggles. The trade-offs and limitations involved warrant an extensive discussion in a separate paper. The combination of case study and simulation requires that researchers are versed in both strands of research, and then undertake an analysis that is going to be considerably more time consuming. This effort would be catalysed by the development of a broadly shared conceptualisation and framework that can act as a channel for dialogue between case and model based work. Ideally this workload can be a reduced with of collaboration among transition scholars, qualitative and simulation researchers. The consistent application of the proposed methodology to transition cases is a step in this direction. Moreover, it will result in the accumulation of some common mechanisms across transition cases, or contexts as is the case in other research fields e.g. Bass diffusion model in management research. Nevertheless, this challenge requires the development of transition indicators for example for the concepts of regime inertia, path dependence, and niche momentum.

Finally, the application of proposed methodology should be sensitive to power and political processes. Researchers engaging in this kind of endeavour should be acutely aware of the politics and power struggles of transitions at two levels. First, regarding actor interests that are stake in the transition and second, actor interests that are supported through the particular case study conceptualization and modelling results. Since transition research is a relatively new area, it is hoped that the proposed methodology will contribute to development of better theory and a more consistent, rigorous and hence powerful methodological approach in transition studies.

\section{Acknowledgements}

The author would like to thank Frank Geels, and four anonymous reviewers for valuable feedback on the paper. 


\section{References}

Abbott, A. (1990). A primer on sequence methods. Organizational Science 1(4), 375-392.

Abbott, A. (2001). Time Matters: On theory and method. University of Chicago press, Chicago, IL.

Abell, P. (2004). Narrative explanation: an alternative to variance-centered explanation? Annual Review of Sociology $30,287-310$.

Abernathy, W.J., Townsend, P.L. (1973). Technology, productivity and process change. Technological Forecasting and Social Change 7, 379-396.

Anderson, O.J.J., Blatt, R., Christianson, M.K., Grant, A.M., Marquis, C., Neuman, E.J., Sonenshein, S., Sutcliffe, K.M. (2006). Understanding mechanisms in organizational research: Reflections from a collective journey. Journal of Management Inquiry, 15, 102-113.

Aramburo, S.A., Castaneda Acevedo, J.A., Morales, Y.O. (2012). Laboratory experiments in the system dynamics field. System Dynamics Review, 28(1), 94-106.

Archer, M.S., 1995. Realist social theory: The morphogenetic approach. Cambridge University Press, Cambridge.

Archer, M., Bhaskar, R., Collier, C., Lawson, T., Norrie, A. (1998). Critical Realism: Essential Readings. Routledge, London, UK

Archer, M.S. (2000). Being human: The Problem of Agency. Cambridge University Press, Cambridge.

Arranz, A.M., (2017). Lessons from the past for sustainability transitions? A meta-analysis of socio-tehnical studies. Global Environmental Change 44, 125-143.

Astley, W.G., Van de Ven, A.H. (1983). Central perspectives and debates in organizational theory. Administrative Science Quarterly 28(2), 245-273.

Bacharach, S.B. (1989). Organizational theories: Some criteria for evaluation. Academy of Management Review 14(4), 496-515.

Bennett, A., Checkel, J.T. (Eds.). (2014). Process Tracing. Cambridge University Press, Cambridge, England.

Barlas, Y., (1989). Multiple tests for validation of system dynamics type of simulation models. European Journal of Operational Research 42, 59-97.

Bennett, A., Checkel, J.T. 2014. Process Tracing: From Metaphor to Analytic Tool. Cambridge University Press

Bergek, A., Jacobsson, S., Carlsson, B., Lindmark, S., Rickne, A. (2008). Analyzing the functional dynamics of technological innovation systems: A scheme of analysis. Research Policy 37, 407-429.

Berkhout, F., Smith, A., Stirling, A. (2004). Socio-technical regimes and transition contexts. In: Elzen, B., Geels, F.W., Green, K. (Eds.), System Innovation and the Transition to Sustainability. Edward Elgar, Cheltenham.

Bhaskar, R. (2008). A Realist Theory of Science. Verso, London, UK.

Bitektine, A. (2008). Prospective case study design qualitative method for deductive theory testing. Organizational Research Methods 11(1), 160-180.

Boudon, R. (1998). Social mechanisms without black boxes. In P., Hedström, R., Swedberg (Eds.) Social mechanisms. An analytical approach to social theory., Cambridge University Press, p 172-203.

Bunge, M. (2004). How does it work? The search for explanatory mechanisms. Philosophy of the Social Sciences 34 , $182-210$.

Burton, R.M., Obel B. (2011). Computational modelling for what-is, what-might-be, and what-should-be studies-and triangulation. Organisation Science 22(5), 1195-1202.

Coenen, L., Benneworth, P., Truffer, B. (2012). Toward a spatial perspective on sustainability transitions. Research Policy 41, 968-979.

Coleman, J.S., 1986. Social theory, social research, and a theory of action. American Journal of Sociology 91(6), 13091335.

Collier, A. (1994). Critical realism: An introduction to the philosophy of Roy Bhaskar. Verson, London.

Collier, D. (2011). Understanding process tracing. Political Science and Politics 4, 823-830.

Corley, K.G., Gioia, D.A. (2011). Building theory about theory building: What constitutes a theoretical constitutes a theoretical contribution? Academy of Management Review 36(1), 12-32.

Cronin, M., Gonzalez, C., Sterman, J.D. (2009). Why don't well-educated adults understand accumulation? A challenge to researchers, educators, and citizens. Organizational Behavior and Human Decision Processes 108(1), 116130.

Cronin, M.A., Gonzalez, C. (2007). Understanding the building blocks of dynamic systems. System Dynamics Review $23,1-17$.

Davis, G.F., Marquis, C. (2005). Prospects for organization theory in the early twenty-first century: Institutional fields and mechanisms. Organization Science 16(4), 332-343.

Davis, J.P., Eisenhardt, K.M., Bingham, C.B. (2007). Developing theory through simulation methods. Academy of Management Review 32(2), 480-499.

De Haan, J., Rotmans, J. (2011). Patterns in transitions: Understanding complex chains of change. Technological Forecasting and Social Change 78(1), 90-102.

De Haan, F.J., Rogers, B.C., Frantzeskaki, N., Brown, R.R. (2015). Transitions through a lens of urban water. Environmental Innovation and Societal Transitions 15, 1-10.

Diehl, E., Sterman, J.D. (1995). Effects of feedback complexity on dynamic decision making. Organizational Behavior and Human Decision Processes 62(2), 198-215. 
DiMaggio, P.J. (1995). Comments on "What theory is not". Administrative Science Quarterly 40(3), 391-397.

Eisenhardt, K.M., Graebner, M.E. (2007). Theory building from cases: Opportunities and challenges. Academy of Management Journal 50(1), 25-32.

Elzen, B., Wieczorek, A. (2005). Transitions towards sustainability through system innovation. Technological Forecasting and Social Change 72, 651-661.

Epstein, J. (2006). Generative Social Science. Studies in Agent-Based Computational Modeling. Princeton University Press, Princeton, NJ.

Fagerberg, J. (2003). Schumpeter and the revival of evolutionary economics: an appraisal of the literature. Journal of Evolutionary Economics 13(2), 125-159.

Ford, D.N., Sterman, J.D., 1998. Expert knowledge elicitation to imrpove formal and mental models. System Dynamics Review 14, 309-340.

Forrester, J.W., 1961. Industrial Dynamics. Cambridge, MA, MIT Press.

Fouquet, R., Pearson, P.J.G. (2012). Past and prospective energy transitions: Insights from history. Energy Policy 50, 1 7.

Foxon, T.J. (2011). A coevolutionary framework for analysing a transition to a sustainable low carbon economy. Ecological Economics 70, 2258-2267.

Geels, F.W. (2002). Technological transitions as evolutionary reconfiguration processes: a multi-level perspective and a case-study. Research Policy 31, 1257-1274.

Geels, F.W. (2004). From sectoral systems of innovation to socio-technical systems: Insights about dynamics and change from sociology and institutional theory. Research Policy 33, 897-920.

Geels, F.W. (2005). Processes and patterns in transitions and system innovations: refining the co-evolutionary multilevel perspective. Technological Forecasting and Social Change 72, 681-696.

Geels, F.W. (2007). Feelings of discontent and the promise of middle range theory for STS: Examples from technology dynamics. Science Technology and Human Values 32(6), 627-651.

Geels, F.W. (2010). Ontologies, sociotechnical transitions (to sustainability) and the multi-level perspective. Research Policy 39, $495-510$.

Geels, F.W. (2011). The multi-level perspective on sustainability transitions: Responses to seven criticisms. Environmental Innovation and Societal Transitions 1(1), 24-40.

Geels, F.W., Schot, J. (2007). Typology of sociotechnical transition pathways. Research Policy 36, 399 - 417.

Geels, F.W., Schot, J.W. (2010). The dynamics of transitions: A socio-technical perspective. in: Grin, J., Rotmans, J., Schot, J. in collaboration with Geels, F.W. and Loorbach, D., 2010, Transitions to Sustainable Development: New Directions in the Study of Long Term Transformative Change, Routledge, pp. 9-87.

Geels, F.W., Kern, F., Fuchs, G., Hinderer, N., Kungl, G., Mylan, J., Neukirch, M., Wassermann, S., (2016a). The enactment of socio-technical transition pathways: A reformulated typology and a comparative multi-level analysis of the German and UK low-carbon electricity transitions (1990-2014). Research Policy 45, 996-913.

Geels, F.W., Berkhout, F., van Vuuren, D.P. (2016b). Bridging analytical approaches for low-carbon transitions. Nature Climate Change 6(6), 576-583.

Genus, A., Coles, A.M. (2008). Rethinking the multi-level perspective of technological transitions. Research Policy 37, 1436-1445.

Gerring, J. (2005). Causation: A unified framework for the social sciences. Journal of Theoretical Politics 17, $163-198$.

Gerring, J. (2010). Causal mechanisms: Yes, but... Comparative Political Studies 43(11), 1499-1526.

Gibson, C.B., Earley, P.C. (2007). Collective cognition in action: Accumulation, interaction, examination and accommodation in the development and operation of group efficacy beliefs in the workplace. Academy of Management Review 32(2), 438-458.

Giddens, A., (1984). The Constitution of Society: Outline of the Theory of Structuration. University of California Press, Berkeley.

Gioia, D.A., Pitre, E. (1990). Multiparadigm perspectives on theory building. Academy of Management Review 15(4), 584-602.

Glennan, S.S. (1996). Mechanisms and the nature of causation. Erkenntnis 44, 49-71.

Goertz, G., Mahoney, J. (2012). A tale of two cultures: Qualitative and quantitative research in the social sciences. Princeton University Press, Princeton, New Jersey.

Goldspink, C. (2002). Methodological implications of complex systems approaches to sociality: simulation as a foundation for knowledge. Journal of Artificial Societies and Social Simulation 5(1)

Goldstone, J.A. (1998). Initial conditions, general laws, path dependence, and explanation in historical sociology. American Journal of Sociology 104(3), 829-845.

Gorissen, L., Spira, F., Meynaerts, E., Valkering, P., Frantzeskaki, N., 2017. Moving towards systemic change? Investigating acceleration dynamics of urban sustainability transitions in the Belgian City of Genk. Journal of Cleaner Production 173(1), 171-185.

Griffin, L.T. (1993). Narrative, event structure analysis and causal interpretation in historical sociology. American Journal of Sociology 98(5), 1094-1133.

Haasnoot, M., Kwakkel, JH., Walker, WE., ter Maat, J. (2013). Dynamic adaptive policy pathways: A method for crafting robust decisions for a deeply uncertain world. Global environmental change 23 (2), 485-498. 
Hackman, J.R. (2003). Learning more by crossing levels: Evidence from airplanes, orchestras and hospitals. Journal of Organizational Behavior 24, 1-18.

Hall, J.R. (1999). Cultures of Inquiry: From Epistemology to Discourse in Sociohistorical Research. Cambridge University Press, Cambridge.

Hannan, M.T., Freeman, J. (1989). Organizational Ecology. Harvard University Press, Cambridge, MA.

Harre, R. (1970). The principles of scientific thinking. University of Chicago Press, Chicago.

Harrison, J.R., Zhiang, L., Carroll, G.R., Carley, K.M. (2007). Simulation modelling in organizational and management research. Academy of Management Review 32(4), 1229-1245.

Hedström, P. (2008). Studying mechanisms to strengthen causal inferences in quantitative research, in: Box-

Hedström, P., Bearman, P. (2009). What is analytical sociology all about? An introductory essay. in: Hedström, P., Bearman, P., (Eds), The Oxford handbook of analytical sociology. Oxford University Press, pp 3-24.

Hedström, P., Swedberg, R. (1998). Social Mechanisms: An Analytical Approach to Social Theory. Cambridge University Press.

Hedström, P., Ylikovksi, P. (2010). Causal mechanisms in the social sciences. Annual Review of Sociology 36, $49-67$.

Hedstrom, P., Bearman, P. (2011). The Oxford handbook of analytical sociology. Oxford University Press, NY.

Hodson, M., Geels, F.W., McMeekin, A., 2017. Reconfiguring urban sustainability transitions, analysing multiplicity. Sustainability 9, 299.

Hekkert, M.P., Suurs, R.A.A., Negro, S.O., Kuhlmann, S., Smits, R.E.H.M., 2007. Functions of Innovation Systems: A new approach for analysing technological change. Technology Forecasting Social Change 74, 413-432.

Helfat, C.E., Finkelstein, S., Mitchell, W., Peteraf, M.A., Singh, H., Teece, D.J., Winter, S.G. (2007). Dynamic capabilities: Understanding strategic change in organizations. Malden, MA, Blackwell, Publishing.

Holtz, G. (2012). The PSM approach to transitions: Bridging the gap between abstract frameworks and tangible entities. Technological Forecasting and Social Change 79, 734-743.

Holtz, G., Alkemade, F., de Haan, F., Köhler, J., Trutnevyte, E., Luthe, T., Halbe, J., Papachristos, G., Chappin, E., Kwakkel, J., Ruutu, S. (2015). Prospects of transition modelling: Position paper of the transition modelling community. Environmental Innovation and Societal Transitions, 17, 41-58.

Homer, J. (1996). Why We Iterate: Scientific Modeling in Theory and Practice. System Dynamics Review 12(1), 1-19.

Janssen M.A., Radtke, N.P., Lee A. (2009). Pattern-oriented modeling of commons dilemma experiments. Adaptive Behavior 17(6), 508-523.

Johnson, B.R., Russo, F., Shoonenboom, J. (2017). Causation in mixed methods research: The meeting of philosophy, science and practice. Journal of Mixed Methods Research, 1-20.

Jick, T. (1979). Mixing qualitative and quantitative methods: Triangulation in action. Administrative Science Quarterly 24, 602-611.

Kagan, J. (2009). The Three Cultures: Natural Sciences, Social Sciences and the Humanities in the 21st Century, Cambridge University Press, Cambridge, UK.

Kahneman, D. (2011). Thinking fast and slow. Allen Lane, US.

Kaidesoja, T. (2013). Overcoming the biases of microfoundationalism: Social mechanisms and collective agents. Philosophy of the Social Sciences 43(3), 301-322.

Köhler, J., de Haan, F., Holtz, G., Kubeczko, K., Moallemi, E.A., Papachristos, G., Chappin, E., 2017. Modelling Sustainability Transitions: An assessment of approaches and challenges. Journal of Artificial Societies and Social Simulation 21(1), 8.

Lane, D.C., 1999. Social theory and system dynamics practice. European Journal of Operational Research 113, 501527.

Lane, D.C., 2008. The emergence and use of diagramming in system dynamics: a critical account. Systems Research and Behavioral Science 25, 3-23.

Langley, A. (1999). Strategies for theorizing from process data. Academy of Management Review 24(4), 691 - 710.

Langley, A. (2007). Process thinking in strategic organization. Strategic Organization 5,271-282.

Langley, A., Smallman, C., Tsoukas, H., Van de Ven, A.H. (2013). Process studies of change in organization and management: Unveiling temporality, activity, and flow. Academy of Management Journal 56(1), 1-13.

Laurisden, E.H., Jørgensen, U. (2010). Sustainable transition of electronic products through waste policy. Research Policy 39, 486-494.

Lerner, R.M., Kauffman, M.B. (1985). The concept of development in contextualism. Developmental Review 5, 309 333.

Luna-Reyes, L.F., Andersen, D.L. (2003). Collecting and analysing qualitative data for system dynamics: Methods and models. System Dynamics Review 19(4), 271-296.

Machamer, P., Darden, L., Craver, C.F. (2000). Thinking about mechanisms. Philosophy of Science, 67(1), 1-25

Mahoney, J. (2000). Strategies of causal inference in small-N analysis. Sociological Methods and Research, 28, 387424.

Mancarella, P. (2014). MES (multi-energy systems): An overview of concepts and evaluation models. Energy 65, 1-17. 
Manicas, P.T. (2006). A Realist Philosophy of Social Science: Explanation and Understanding. Cambridge University Press, Cambridge, U.K.

Markard, J., Raven, R., Truffer, B. (2012). Sustainability transitions: An emerging field of research and its prospects. Research Policy, 41, 955-967.

Markard, J., Truffer, B. (2008). Technological Innovation systems and the multi-level perspective: Towards an integrated framework. Research Policy, 37, 596-615.

Martinez-Moyano, I.J., Richardson, G.P., 2013. Best practices in system dynamics modeling. System dynamics Review 29(2), 102-123.

Mayntz, R. (2004). Mechanisms in the analysis of social macro-phenomena. Philosophy of the Social Sciences, 34, $237-$ 254.

McAdam, D., Tarrow, S., Tilly, C. (2001). Dynamics of Contention. Cambridge University Press.

Mcdowall, W., 2014. Exploring possible transition pathways for hydrogen energy: A hybrid approach using sociotechnical scenarios and energy system modelling. Futures 63, 1-14.

McMeekin, A., Southerton, D. (2012). Sustainability transitions and final consumption: practices and socio-technical systems. Technology Analysis and Strategic Management, 24(4), 345-361.

Merton, R.K. (1968). Social Theory and Social Structure. The Free Press, New York.

Merton, R.K., Rossi, A.S. (1968). Contributions to the Theory of Reference Group Behavior. p. 279-334 in Social Theory and Social Structure. New York: The Free Press.

Mingers, J. (2014). Systems Thinking, Critical Realism and Philosophy: A Confluence of Ideas. Routledge, Oxon, UK.

Mingers, J., Standing, C., 2017. Why things happen - Developing the critical realist view of causal mechanisms. Information and Organization 27(3), 171-189.

Mintzberg, H. (2005). Developing theory about the development of theory. in: K.G., Smith, M.A., Hitt (Eds.), Great minds in management: The process of theory development, 355-372, Oxford University Press.

Mitchell, T.R., James, L.R. (2001). Building better theory time and the specification of when things happen. Academy of Management Review 26(4), 530 - 547.

Mitroff, I., Emshoff J. (1979). On strategic assumption making: a dialectical approach to policy and planning. Academy of Management Review 4(1), 1 - 12.

Moallemi, E.A., Aye, L., de Haan, F., Webb, J.M. 2017a. A dual narrative-modelling approach for evaluating sociotechnical transitions in electricity sectors. Journal of Cleaner Production 162, 1210-1224.

Moallemi, E.A., de Haan, F., Kwakkel, J,. Aye, L., 2017b. Narrative-informed exploratory analysis of energy transition pathways: A case study of India's electricity sector. Energy Policy 110, 271-287.

Mohr, L.B. (1982). Explaining organizational behaviour. Jossey-Bass, San Fransisco.

Morgan, G. (1983). Beyond method. Sage, Newbury Park, CA.

Naber, R., Raven, R., Kouw, M., Dassen, T., 2017. Scaling up sustainable energy innovations. Energy Policy 110, $342-$ 354.

Nuzzo, R., (2015). How scientists fool themselves - and how they can stop. Nature 526(7572), 182-185.

Opp, K.D. (2005). Explanations by mechanisms in the social sciences. Problems, advantages and alternatives. Mind and Society 4, 163-178.

Oreskes, N., Shrader-Frechette, K., Belitz, K. (1994). Verification, validation and confirmation of numerical models in the earth sciences. Science 263(5147), 641-646.

Papachristos, G. (2011). A System Dynamics Model of Socio-technical Regime Transitions. Environmental Innovation and Societal Transitions 1(2), $202-233$.

Papachristos, G. (2014). Towards multi-system sociotechnical transitions: why simulate. Technology Analysis and Strategic Management 26(9), 1037-1055.

Papachristos, G., (2017). Diversity in technology competition. The link between platforms and sociotechnical transitions. Renewable and Sustainable Energy Reviews 73, 291-306.

Papachristos, G., Adamides, E. (2016). A retroductive systems-based methodology for socio-technical transitions research. Technology Forecasting and Social Change 108, 1-14.

Papachristos, G., Sofianos, A., Adamides, E. (2013). System interactions in socio-technical transitions: Extending the multi-level perspective. Environmental Innovation and Societal Transitions 7, 53 - 69.

Pentland, B.T. (1999). Building process theory with narrative: from description to explanation. Academy of Management Review 24, 711-724

Pedriana, N. (2005). Rational choice, structural context and increasing returns: A strategy for analytic narrative in historical sociology. Sociological Methods and Research 33, 349-382.

Pettigrew, A.M. (1997). What is a processual analysis. Scandinavian Journal of Management 13, 37-348.

Pfeffer, J. (1982). Organizations and organization theory. Pitman, Boston.

Pidd, M. (2004). Bringing it all together, in: Pidd, M. (Ed.), Systems modelling: Theory and practice. Wiley, Chichester, UK.

Poole, M.S., Van de Ven, A.H. (2004). Handbook of organizational change and innovation. Oxford University Press, New York.

Rahmandad, H., Sterman, J. (2008). Heterogeneity and network structure in the dynamics of diffusion: Comparing agent-based and differential equation models. Management Science 54(5), 998-1014. 
Rahmandad, H., Sterman, J.D. (2012). Reporting guidelines for simulation based research in social sciences. System Dynamics Review 28(4), 396-411.

Railsback, S.F., Johnson, M.D. (2011). Pattern oriented modelling of bird foraging and pest control in coffee farms, Ecological Modelling 222(18), 3305-3319.

Randers, J. (1973). Conceptualizing dynamic models of social systems: Lessons from a study of social change. PhD thesis, MIT, US.

Raven, R. (2007). Niche accumulation and hybridisation strategies in transition processes towards a sustainable energy system: An assessment of differences and pitfalls. Energy Policy 35, 2390-2400.

Raven, R., Verbong, G. (2007). Multi-regime interactions in the Dutch energy sector: the case of combined heat and power technologies in the Netherlands 1970-2000. Technology Analysis \& Strategic Management 19(4), 491507

Richardson, G.P., Pugh III, A.L. (1981) Introduction to System Dynamics Modeling with Dynamo. MIT Press, Cambridge, Massachusetts.

Richardson, K. (2005). The hegemony of the physical sciences: an exploration in complexity thinking. Futures $37,615-$ 653.

Rip, A., Kemp, R. (1998). Technological change. In (eds) S. Rayner, E.L. Malone, Human Choice and Climate Change, vol. 2. Battelle Press, Columbus, OH, 327-399.

Rogers, E. (2003). The diffusion of innovations. 5th edition, Free Press.

Rogelj, J., Luderer, G., Pietzcker, R.C., Kriegler, E., Schaeffer, M., Krey, V., Riahi, K. (2015). Energy system transformations for limiting end-of-century warming to below 1.5C. Nature Climate Change 5, 519-527.

Sayer, A. (1992). Method in social science: A realist approach. Routledge, UK.

Sayer, A. (2000). Realism and social science. Sage Publications, UK.

Scharpf, F.W. (1997). Games real actors play: Actor-centered institutionalism in policy research. West Press, Boulder, US.

Schelling, T.C. (1978). Micromotives and Macrobehavior. New York: W. W. Norton.

Shove, E., Walker, G. (2007). Caution! Transitions ahead: politics, practice, and sustainable transition management. Environment and Planning A 39, 763-770.

Shove, E. 2012. The shadowy side of innovation: Unmaking and sustainability. Technology Analysis and Strategic Management 24(4), 363-75.

Siggelkow, N. (2007). Persuasion with case studies. Academy of Management Journal 50(1), 20-24.

Smith, A., Stirling, A., Berkhout, F. (2005). The governance of sustainable sociotechnical transitions. Research Policy 34, 1491-1510.

Smith, A., Voß, J.P., Grin, J. (2010). Innovation studies and sustainability transitions: The allure of the multi-level perspective and its challenges. Research Policy 39, 435-448.

Steihilber, S., Wells, P., Thankappan, S. (2013). Socio-technical inertia: Understanding the barriers to electric vehicles. Energy Policy 60, 531-539.

Sterman, J.D, Sweeney, L.B. (2007). Understanding public complacency about climate change: adults' mental models of climate change violate conservation of matter. Climatic Change 80(3-4), 213-238.

Sterman, J.D. (1989a). Misperceptions of feedback in dynamic decision making. Organizational Behaviour and Human Decision Processes 43(3), 301-335.

Sterman, J.D. (1989b). Modelling managerial behaviour: Misperceptions of feedback in a dynamic decision making experiment, Management Science 35(3), 321-339.

Sterman, J.D. (1994). Learning in and about complex systems. System Dynamics Review 10, 291-330.

Sterman, J.D. (2000). Business Dynamics: systems thinking and modelling for a complex world. McGraw Hill, New York.

Sterman, J.D. (2008). Risk Communication on climate: mental models and mass balance. Science 322, 532-533.

Sterman, J.D. (2010). Does formal system dynamics straining improve people's understanding of accumulation?. System Dynamics Review, 26(4), 316-334.

Stinchcombe, A.L. (1998). Monopolist Competition as a Mechanism: Corporations, Universities, and Nation-States in Competitive Fields. In (eds) P. Hedström, R. Swedberg, Social Mechanisms: An Analytical Approach to Social Theory, Cambridge University Press, 267-305.

Sutton, R.I., Staw, B.M. (1995). What theory is not, Administrative Science Quarterly, 40(3), 371-384.

Tashakkori, A., Teddlie, C. (1998). Mixed Methodology. Combining Qualitative and Quantitative Approaches. Sage, Thousand Oaks.

Tilly, C. (2001). Mechanisms in political processes. Annual Review of Political Science, 3, 21-41.

Torres, P.J. (2009). A modified conception of mechanisms. Erkenntnis, 71, 233-251.

Trochim, W.M.K. (1989). Outcome pattern matching and program theory. Evaluation and Program Planning 12, 355366.

Trutnevyte, E., Barton, J., O'Grady, A., Ogunkunle, D., Pudjianto, D., Robertson, E. (2014). Linking a storyline with multiple models: A cross-scale study of the UK power system transition. Technological Forecasting and Social Change 89, 26-42. 
Tsoukas, H. (1989). The validity of idiographic research explanations. Academy of Management Review 14(4), 551561.

Tukker, A. (2015). Product services for a resource-efficient and circular economy - a review. Journal of Cleaner Production 97, 76-91.

Turnheim, B., Geels, F.W. (2012). Regime destabilisation as the flipside of energy transitions: lessons from the history of the British coal industry (1913-1997). Energy Policy 50, 35-49.

Turnheim, B., Geels, F.W., (2013). The destabilisation of existing regimes: Confronting a multi-dimensional framework with a case study of the British coal industry (1913-1967). Research Policy 42, 1749-1767.

Turnheim, B., Berkhout, F., Geels, F., Hof, A., McMeekin, A., Nykvist, B., van Vuuren, D. (2015). Evaluating sustainability transitions pathways: Bridging analytical approaches to address governance challenges. Global Environmental Change 35, 239-253.

Van de Ven, A.H. (1992). Suggestions for studying strategy process: a research note. Strategic Management Journal 13, 169-188.

Van de Ven, A.H. (2007). Engaged scholarship: A guide for organizational and social research. Oxford, Oxford University Press.

Van den Bergh, J.C.J.M., 2011. Environment versus growth - A growth of 'degrowth' and a plea for 'a-growth'. Ecological Economics 70,881-890.

Van den Bergh, J.C.J.M., Truffer, B., Kallis, G. (2011). Environmental innovation and societal transitions. Environmental Innovation and Societal Transitions 1, 1-23.

Vasileiadou, E., Safarzynska, K. (2010). Transitions: Taking complexity seriously. Futures 42, 1176-1186.

Voss, J., Bauknecht, D., Kemp, R., (Eds.), (2006). Reflexive Governance for Sustainable Development. Cheltenham, Edward Elgar.

Weick, K. (1979). The social psychology of organizing. Reading, MA, Addison-Wesley.

Weick, K.E. (1989). Theory construction as disciplined imagination. Academy of Management Review 14(4), 516-531.

Weick, K.E., Roberts, K.H. (1993). Collective mind in organizations Heedful interrelating on flight decks. Administrative Science Quarterly 38(3), 357-381.

Weick, K.E. (1995). What theory is not theorizing is. Administrative Science Quarterly 40(3), 385-390.

Whetten, D.A. (1989). What constitutes a theoretical contribution. Academy of Management Review 14(4), 490-495.

Wilson, J.M., Goodman, P.S., Cronin, M.A. (2007). Group learning. Academy of Management Review 32(4), 1041 1059.

Winsberg, E. (2006). Models of success versus the success of models: Reliability without truth. Synthese 152, 1-19.

Wolstenholme, E. (1990). System Enquiry: A System Dynamics Approach. Wiley, Chichester.

Woodward, J. (2002). What is a mechanism? A counterfactual account. Philosophy of Science 69, 366-377.

Wuisman, J.J.J.M. (2005). The logic of scientific discovery in critical realist social scientific research. Journal of Critical Realism 4(2), 366-394.

Yin, R.K. (2003). Case study research: Design and methods, 3rd edition, Sage Publications, CA, US. 